\title{
Natural Methods to Assist Delivery during the Second Stage of Labour: Part Ill:Timing and Type of Pushing
}

\section{Panos Antsaklis, Maria Papamichail, Marianna Theodora, Michael Syndos, George Daskalakis, Dimitris Loutradis}

$1^{\text {st }}$ Department of Obstetrics and Gynecology, "Alexandra" Hospital, National and Kapodistrian University of Athens, Greece

Corresponding Author

Maria Papamichail, Medical Doctor - University of Athens, e-mail: mapapam@hotmail.com

\section{Abstract}

As women experience their partirution in health care facilities, they expect the best possible outcomes for them and their newborn, as interventions are supposed to be made accurately. Women in labour, are often directed to push as soon as the cervix reaches full dilation but this technique contradicts normal physiology. In contrast, when a woman is free to follow her instincts, by making spontaneous bearing down efforts, the time spending for pushing might be decreased and also urodynamic parameters after delivery are improved. In this second part of the effort made for detection of natural methods to assist delivery, it is presented an overview of the physiology of both the directed and the spontaneous pushing and a review of the literature suggesting that women in labour should be letting free to choose the labour technique that they prefer in terms of timing and type of the bearing down efforts.

\section{Introduction}

It is a well-established fact that nowadays a remarkable percentage of women globally, experience their parturition in health care facilities. In different parts of the world and sometimes in different cases in the same health centre, contrasts are met daily: some women are being provided with interventions they do not need and maybe in they are done in a wrong point of time, while others are not receiving the appropriate interventions in terms of time and situation.
The scope of this second part of the article "Natural Methods to Assist Delivery during the Second Stage of Labour" is to present the timing of pushing in terms of immediate or delayed pushing and the type of pushing including directed or spontaneous bearing down efforts. This information has the potential to provide evidence for the best obstetrical practice and to give lines for a better parturition with the least possible complications, discomfort and pain for the mother. 


\section{Type of pushing (directed vs spontaneous} efforts)

It is a common method, during the second stage of labour, the obstetricians or the midwives who are in charge to manage the parturition of a woman, to give directions for how to push when a uterine contraction occurs. Directions are more often given as soon as a full cervical dilatation is observed ${ }^{1}$. When a uterine contraction begins, women are told to take a deep, cleansing breath, then to hold their breath as long and as hard is possible and to push towards their vagina $^{2}$. The directed pushing effort is encouraged to be occurred with a closed- glottis breathing activity and its duration to be at least 10 seconds $^{3,4}$, and women are told to repeat the whole procedure for two or three times per contraction. This technique is called the Valsalva Maneuver (VM). Nevertheless, there is not clear evidence for the effectiveness of this method, and even worst, second stage practices like this, might lead to adverse maternal outcomes, such as increased rates of caesarean sections, increased maternal fatigue, greater possibilities of perineal lacerations and therefore pelvic floor and sexual dysfunction and urinary or fecal incontinence ${ }^{1,5-8}$. This is mainly due to the enormous force which is produced by both the descending fetal head and the mother's voluntary pushing effort and which is applied to the perineal tissue surrounding the fetal head, contributing to a great biomechanical misalignment ${ }^{1}$. Moreover, unfavorable neonatal outcomes such as fetal deoxygenation, acidemia, more frequently observed abnormal heart rate patterns and delay in spontaneous recovery for fetal heart rate decelerations and low Apgar scores might also be presented ${ }^{2}$. The pathophysiologic explanation for the adverse neonatal outcomes is that when a pushing effort lasts for more than six seconds, maternal haemodynamic measurements are altered: the venous return to the heart is inhibited, the cardiac output, the blood pressure and therefore placenta blood perfusion decrease ${ }^{7}$, leading to a reduced blood flow and oxygen to the fetus. ${ }^{5,8}$

\section{The physiology of the natural - spontaneous bearing down effort:}

During the second stage of labour, and specifically during a uterine contraction, breathing alters from an unconscious act to a voluntary and controlled operation, urged by the normal physiologic norms of parturition ${ }^{1}$. Furthermore, as the presenting part of the fetus descends during a contraction, a compression occurs in both the bladder and the rectum, generating a reflex resulting to a strong urge to bear down, or 'push'. Therefore, the combination of involuntary intrauterine contractions and voluntary-but with a non-resisting willing- expulsive efforts, are mobilizing the respiratory, abdominal and perineal muscles. As a result, the fetus comes throughout the birth canal ${ }^{9}$. Many authors occupied with normal delivery, argue that leaving the woman in labour free to follow her own instincts for how and when to push, might prevent perineal tears and therefore making the possibility of pelvic or urineal dysfunction smaller ${ }^{10}$, as the spontaneous pushing allows a slower and controlled descent of the fetus, resulting to a gradual stretching of the perineal muscles. In addition, pushing when an irresistible urge is present, makes the pressure that is applied on the anterior vaginal wall, the cervical ligaments and to the connective tissue supporting the vaginal walls smaller, as it is not applied unless the fetus has already started to descend.

The spontaneous bearing down efforts begin early in the second stage of labour, they have low amplitude, they are not met in every uterine contraction, they vary in intensity ${ }^{11}$, and as the fetus continues its descent through the birth canal, pushing efforts' force is increasing progressively. In fact, the woman starts to push when the uterine contraction meets a threshold pressure of $30 \mathrm{mmHg}^{5,12}$. When this thresh- 
old has been reached, the woman begins to push from a resting respiratory volume ${ }^{4}$, and she generally releases the air during the effort. Women push an average duration of 5 seconds and the pushing effort barely lasts more than 6 seconds. During the effort, women take several breaths for approximately 2 seconds each, and push approximately 3 to 5 times per contraction. The $75 \%$ of the spontaneous bearing down efforts occur with an open-glottis ${ }^{12-13}$. Generally, when the women in labour are not given directions for their pushing efforts, a biphasic pattern of the bearing down efforts has been observed ${ }^{13}$. Throughout the first phase, the fetus is descending passively, while in the second phase, as the fetal head reached the perineum, pushing efforts per contraction are increasing in terms of frequency and force ${ }^{13-14}$. This natural pattern, evokes the Ferguson's reflex, where oxytocin release is increased, labour in naturally being augmented, and the bearing down efforts are more efficient and less stressful ${ }^{33}$.

\section{Literature Review}

In order to get clear wherever a directed or a spontaneous bearing down effort is more beneficial for both the mother and the neonate, several clinical trials took place. A large Cochrane Analysis that occurred in $2017^{1}$, included 8 trials (884 womenwith or without epidural analgesia) and studied the outcomes of women grouped in two arms: the first included women who were left to follow their own instincts, without giving any specific direction for the pushing technique, while in the second arm, women were given directions for making the Valsalva Maneuver, as it was described above, as soon as cervical dilatation had reached $10 \mathrm{~cm}$. Despite the effort made, the authors couldn't reach to an evidence-based conclusion, as the outcomes measured for both the mother and neonate, did not show statistical significant difference between the two studied groups, in any of the outcomes comprised. The maternal outcomes included the duration of the second stage, the duration the women spent for pushing, the rates of spontaneous vaginal deliveries compared to both caesarean sections and instrumental vaginal deliveries, the need for oxytocin augmentation, the possibility of episiotomy, third and fourth degree perineal lacerations, maternal fatigue and satisfaction. The neonatal outcomes included Apgar score below seven in the fifth minute and the possibility for the neonate to be transmitted to an intensive care unit. Nevertheless, when a sensitivity analysis was done, excluding a quasi-randomised trial, the total duration of the second stage of labour was statistically significant shorter - for approximately 17 minutesin women in the directed pushing group (MD 17.62, 95\% CI 5.28-29.95, P<0.05), although the time spent pushing was statistically significant shorter - for 15 minutes- in women in the spontaneous pushing group (MD -15.22, 95\% CI -21.64-8.80).

A systematic review, run by Prins et $\mathrm{al}^{16}$ in 2011, included low-risk, healthy, nulliparous women presenting in labour at term. None of the women participating to the survey had used epidural analgesia for pain relief. The only disagreement with the 2017 Analysis was the duration of the second stage of labour. In this study, the women who were given directions to use the Valsalva Maneuver, were experienced a 18,59 minutes shorter second stage (MD 18.59; 95\% CI 0.46-36.73), and when a sensitivity analysis was carried, excluding a small trial with a huge reduction in the second stage of labour, the mean difference was eliminated to 9.75 minutes (MD 9.75; 95\% CI 2.43-17.06). However, the authors commented that this result carries uncertain clinical significance, as this reduction is not associated with any difference in instrumental vaginal deliveries or caesarean sections. The remaining outcomes studied were not statistically significant and they are presented in table 1 . As a conclusion, it was suggested, that as certain recommendation cannot 
be performed, every woman should be led free to choose her own pushing technique.

Schaffer et $\mathrm{al}^{10}$, studied the urodynamic effects of the spontaneous $v$ s the directed pushing efforts. The women who were participating to the survey were all nuliparus and they were grouped in the same groups

Table 1. Synopsis of the articles concerning the type of pushing

STUDY-AUTHORS- YEAR-
ELIGIBLE WOMEN
Cochrane Analysis
Lemos et al ${ }^{1} \mathbf{2 0 1 7}$
- nulliparus or multiparus
- low risk
- absence of intrapartal
comblications
- gestational age: 37 to 42
weeks
- vertex presentation
- alive - single fetus
- with or without epidural
analgesia

Systematic Review Prins et $\mathbf{a l}^{16} \mathbf{2 0 1 1}$

- nulliparus

- healthy- low riskwithout comblications

- gestational age > 36 weeks

- without epidural analgesia

\section{STATISTICAL SIGNIFICANT OUTCOMES}

None With sensitivity analysis:

- Reduced duration of second stage in the directed group(MD 17.62, 95\% CI 5.28-29.95, $\mathrm{P}<0.05$ )

- Reduced pushing time in the spontaneous group (MD $-15.22,95 \%$ CI -21.648.80).

\section{Maternal}

- Reduced duration of second stage in the directed group(MD 18.59, 95\% CI 0.46-36.73)

- With sensitivity analysis:

- 9.75; 95\% CI 2.43-17.06
NON-STATISTICAL SIGNIFICANT OUTCOMES

\section{Maternal:}

- Second Stage Duration

- Perineal Lacerations (3rd and 4th degree)

- Episiotomy

- Pushing Duration

- Oxytocin augmentation

- Spontaneous Vaginal Delivery

- Instrumental Vaginal Delivery

- Caesarean Section

- Fatigue after Delivery

- Maternal Satisfaction

- Urinary Incontinence

- Detrusor Overactivity

Neonatal

- Admission to neonatal intensive care

- five- minute Apgar score less than seven

- Low umbilical cord blood pH

- Delivery room resusciation

Maternal

- Instrumental Vaginal Delivery

- Caesarean Section

- Episiotomy

- Perineal Repair

- Perinal tears

- Maternal Satisfaction

Neonatal

- five- minute Apgar score less than seven

- mean umbilical artery $\mathrm{pH}$

- mean umbilical vein $\mathrm{pH}$

- umbilical artery $\mathrm{pH}<7.20$

- need for resuscitation

- admission to neonatal intensive care

\section{AUTHORS' CONCLUSION- SUGGESTIONS}

It is impossible to reach a conclusive result, as there was no clear evidence supporting the beneficial effects for either the directed or the spontaneous pushing.

Authors suggested that women should be encouraged to bear down according to their comfort and preference.
The existing data do not support the use of the Valsalva Maneuver as routine technique, but sample sizes are small, in order to be conclusively curtain.

Spontaneous pushing might be a good practice, but women should choose their own pushing technique. 
Table 1. Synopsis of the articles concerning the type of pushing (condinued)

STUDY-AUTHORS- YEAR-
ELIGIBLE WOMEN
Randomized Clinical
Trial Schaffer et al $^{\mathbf{1 0}}$
$\mathbf{2 0 0 5}$
- Nulliparus
- Spontaneous Active
Labour
- Uncomblicated
Pregnancies
- gestational age: 36 to 41
weeks
- cephalic presentation

Randomized Clinical Trial Bloom et al ${ }^{17} 2006$

- Nulliparus

- Spontaneous Active Labour

- Uncomblicated Pregnancies

- gestational age: 36 to 41 weeks

- cephalic presentation

Randomized Clinical Trial Yildimir et $\mathbf{a l}^{20}$

2008

- nulliparus

- Low risk- without complications

- healthy single fetus (EFW 2500-3999 g)

- vertex presentation

\section{STATISTICAL SIGNIFICANT OUTCOMES}

\section{Maternal}

- First urge to push was decreased in the coached group (MD -41.5, $\mathrm{P}=0.025$ )

- Bladder Capacity was group (MD - 54.6, $\mathrm{P}=0.051$ )

\section{Maternal}

- Reduction to second stage duration for 13 minutes ( $\mathrm{P}=0.014$ ) in the coached group

- The possibility of meconium-stained amniotic fluid was increased in the coached group $(\mathrm{P}=0.028)$. decreased in the coached

\section{NON-STATISTICAL SIGNIFICANT OUTCOMES \\ Maternal}

- duration of the second stage

- oxytocin augmentation

- epidural analgesia

- episiotomy

- Third and fourth degree perineal lacerations

- instrumental vaginal delivery

- maximum urethral closure pressure

- functional urethral length maximum flow rate dectrusor pressure at peak flow

- dectrusor overactivity

- urodynamic stress incontinence

- positive Valsalva leak point pressure

\section{Neonatal: Macrosomia}

\section{Maternal}

- prolonged second stage of labour

- episiotomy

- perineal lacerations

- Spontaneous vaginal delivery

- instrumental vaginal delivery

- Caesarean Section

\section{Neonatal}

- 5-min Apgar score 7 or less

- Umbilical artery pH

- Delivery room resuscitation

- Chorioamnionitis

- NICU admission

\section{Maternal}

- The duration of the second stage of labor was shorter in the spontaneous pushing group (MD -9.3, $\mathrm{P}=0.045$ )

- The duration of the expulsion phase was shorter in the spontaneous pushing group (MD -5.2, $\mathrm{P}=0.001$ )

\section{Maternal}

- oxytocin augmentation

- episiotomy

- perineal tears

- postpartum hemorrhage

Neonatal

- Nonreassuring fetal surveillance pattern

- umbilical artery ph $<7.2$

\section{AUTHORS' CONCLUSION- SUGGESTIONS}

Coached bearing down efforts carry harmful effects for the pelvic and urodynamic function of the mother and it should be avoided, unless specific are present.

Neither the coached nor the uncoached pushing efforts can be suggested as superior.
Spontaneous Pushing should be encouraged, as it can short the duration of the second stage of labour and the expulsion phase. Neonatal outcomes, maternal satisfaction and effectiveness are also improved with this technique. 
Table 1. Synopsis of the articles concerning the type of pushing (condinued)

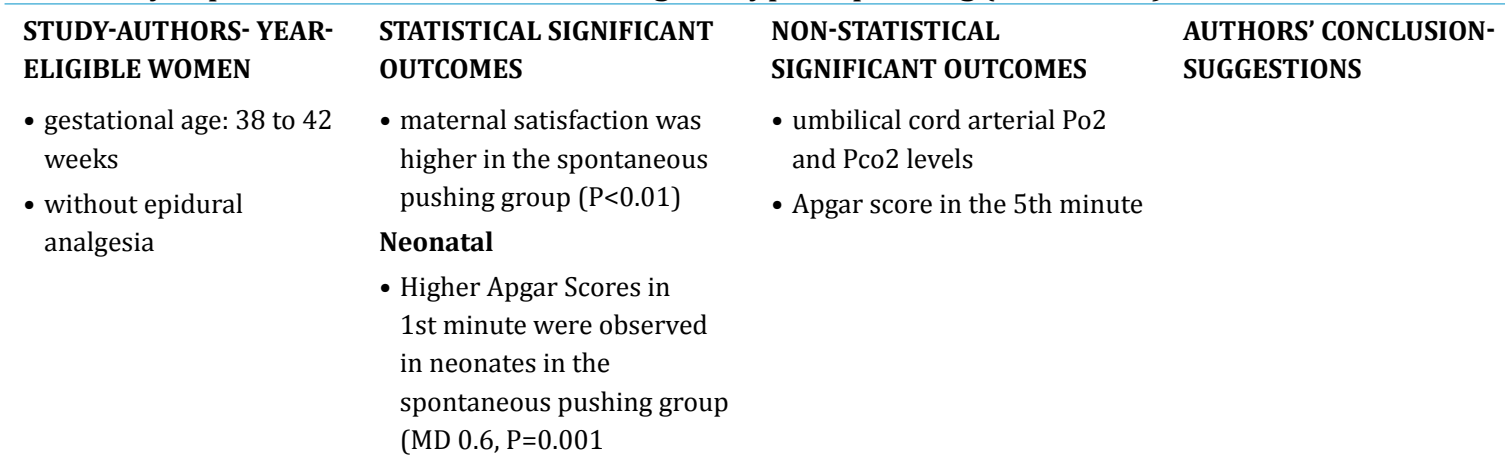

as in the Cochrane Analysis, although the authots used to call the directed pushing as 'coached' and the spontaneous pushing efforts as 'un-coached'. The conclusions concerning the duration of the second stage, the need for oxytocin augmentation, episiotomies, third, fourth degree perineal lacerations and instrumental vaginal deliveries rates were aligned with the study discussed above; they couldn't find a relation with the type of pushing. However, as they run urodynamic tests three months postpartum, they concluded that first urge to void (MD $-41.5, \mathrm{P}=0.025$ ) and the bladder capacity (MD $-54.6, \mathrm{P}=0.051$ ) were decreased in the coached group. The coached pushing efforts had not clear relation with the maximum urethral closure pressure $(\mathrm{P}=0.264)$, the functional urethral length $(\mathrm{P}=0.548)$, the maximum flow rate $(\mathrm{P}=0.231)$, dectrusor pressure at peak flow $(\mathrm{P}=0.104)$, dectrusor overactivity $(\mathrm{P}=0.170)$, urodynamic stress incontinence $(\mathrm{P}=0.443)$, and the positive Valsalva leak point pressure $(\mathrm{P}=0.072)$. The authors concluded that the coaching during the second stage of labour, carries adverse effects for the pelvic and urodynamic function of the mother and therefore should be avoided, unless specific indications - concerning either the mother i.e. prolonged second stage or the fetus i.e. nonreassuring fetal heart rate patterns - are present.

Bloom et $\mathrm{al}^{16}$, run a similar survey with Schaffer et $\mathrm{al}$, but they were focused in the obstetrical outcomes and their association with the type of pushing. They concluded that the second stage of labour was 13 minutes shorter $(\mathrm{P}=0.014)$ in women who were experienced coached pushing. Perry et $\mathrm{al}^{18}$ suggested that this reduction in the second stage's duration is due to the increased intrauterine pressure for about $62 \%$ when the Valsalva Maneuver is applied, during the uterine contraction, compared to the intrauterine pressure when a contraction occurs, without any action from the mother ${ }^{19}$. Another statistically significant result, but with uncertain clinical importance, is that in the group that the Valsalva Maneuver was followed, the incidence of meconium-stained amniotic fluid was approximately twice as high in the group where the natural pushing efforts were followed $(\mathrm{P}=0.028)$. Although, as it is mentioned above, this can't be evaluated, as this situation was mainly diagnosed during the first stage of labour and it was not aligned with any harmful consequence for the fetal-neonatal health. The other studied outcomes (prolonged second stage of labour- exceeding 2 hours in women without epidural analgesia or exceeding 3 hours in women with epidural analgesia, route of delivery- spontaneous vaginal delivery, instrumental vaginal delivery or caesarean section, episiotomy rates, chorioamnionitis rates and the need for epidural analgesia or oxytocin augmentation) were not statistically significant. The authors concluded that there are neither benefits nor 
harmful effects - at least short-term- for both the mother and fetus, concerning the type of pushing during the second stage of labour, and therefore a conclusive sentence cannot be suggested.

Yildimir et $\mathrm{al}^{20}$, run a clinical trial in 2008 and their results are quite interesting, as they are partly in disagreement with the vast majority of the literature since today. They found that the duration of the second stage (MD -9.3, $\mathrm{P}=0.045$ ) such as the duration of the expulsion phase (MD -5.2, $\mathrm{P}=0.001$ ) ware statistically significant shorter in women who were randomized to the spontaneous pushing technique. In addition, the neonates in this group were more likely to have higher Apgar scores in the first minute (MD 0.6, $\mathrm{P}=0.001$ ) and their mothers were noted that they were more satisfied with their childbirth $(\mathrm{P}<0.01)$. The non-statistical significant outcomes are summarized in Table 1. One possible reason for this misalignment with the existing literature is that women were not push immediately, but they begun their pushing efforts as long as the fetal head was visible in the introitus.

In Table 1, the results from the studies discussed above are summarized. Furthermore, some outcomes which have not been discussed in the text for room's sake are also presented in the table.

\section{Timing of pushing (immediate vs delayed)}

Another technique which has been established in medical daily routine during labour, is to encourage the woman to push as soon as the cervix reaches the $10 \mathrm{~cm}$ dilatation, regardless the station of the fetal presenting part, and this technique is called "the immediate pushing technique" 8,21 . However, there is evidence supporting that the strong urge to push might be present after or even before the observation of the full cervical dilatation ${ }^{35}$.

Nowadays, more and more women are choosing epidural analgesia for pain relief during labour ${ }^{2}$. However, this analgesia method carries some disad- vantages, such as an increased duration of the second stage, resulting to increased rates of instrumental vaginal delivery ${ }^{23}$. Pathophysiologically, this situation occurs, because epidural analgesia blocks sensory and motor nerves, the perineal muscles are relaxed, the fetal head delays or fails to rotate internally, the mother feels a weak urge to push and her efforts are less efficient, as the bearing down reflex is abated ${ }^{24-25}$.

In order to eliminate the adverse effects of epidural analgesia, Maresh et $\mathrm{al}^{26}$ firstly suggested the "Laboring Down" technique. When a woman follows the laboring down technique, she does not begin to push, unless she feels an irresistible urge to push, the fetal head is being visualized in the vaginal introtius, or a specific period of time passes, counting from the moment when the full cervix dilation has been observed ${ }^{25}$. Many authors argue that this technique is beneficial, especially in women who are experiencing their partition with epidural analgesia, as the pushing efforts are more efficient, due to the spontaneous descent and rotation of the fetal head, leading to better positioned fetus in the birth canal $^{27}$. As a result, instrumental vaginal delivery rates and maternal fatigue are decreased ${ }^{28-29}$. In addition, in the existing literature there are many articles and surveys claiming that laboring down may also protect the pelvic floor ${ }^{8}$, and one of the indicating factors is the possible reduction in the necessity of an instrumental vaginal delivery ${ }^{35}$. Moreover, the fetus might also benefits from the delayed pushing method, as the duration of pushing declines; blood flow towards the placenta does not diminish, resulting to better oxygenation levels and therefore a dip in abnormal fetal heart rate patterns ${ }^{37}$. Finally, according to Fraser et $\mathrm{al}^{7}$, the women that have the greatest benefits from adopting the delayed pushing technique are those whose fetuses are in a high or a transverse position.

Nevertheless, in the existing literature encompassed with the benefits and the possible negative 
effects of the delayed pushing technique, couldn't reach to a conclusive result that is able to recommend a uniform practice for the timing of pushing. The articles and trials with the greater quality regarding their methodology and their interesting outcomes are discussing below and their outcomes are summarized in Table 2.

Lemos et $\mathrm{al}^{1}$, in their large Cochrane Analysis, studied also the timing of pushing and they grouped the women in two arms: the former included women who were following the classic immediate pushing technique and the latter included women who were following the delayed pushing technique. The conclusions were quite interesting: they found a statistical significant increase in the duration of the second stage of labour in the delayed pushing group, when both nulliparus and multiparus women were studied (MD 56.40, 95\% CI 42.05 to 70.76). This difference was also statistical significant when women were sub-grouped by parity: the second stage was 56.12 (MD 56.12, 95\% CI 39.29 to 72.96) and 38.80 (MD 38.80, 95\% CI 29.16 to 48.44 ) minutes longer in nulliparus and multiparus women respectively. Interestingly, the duration of the active second stage, defined as the time spent for pushing, was statistical significant shorter in women in the group where the delayed pushing technique was followed. When both nulliparus and multiparus women were studied the mean reduction was 19.05 minutes (MD -19.05, 95\% CI -32.27 - -5.83). The reduction of pushing duration was larger in nulliparus women compared to multiparus, although the difference remained statistical significant. The active second stage was 21.30 (MD -21.30, 95\% CI -36.87 to -5.73 ) and 11.35 (MD -11.35, 95\% CI -18.19 to -4.51 ) minutes shorter in nulliparus and multiparus women respectively. In addition, there was also a slight increase in spontaneous vaginal delivery rates in the latter group (RR 1.07, 95\% CI 1.03 to 1.11) and there was no difference in nullipa- rus or multiparus women. However, the caesarean section rates (RR $0.83,95 \% \mathrm{CI} 0.65$ to 1.05 ) and the instrumental vaginal delivery rates (RR $0.89,95 \%$ CI 0.74 to 1.07 ) were not statistical significant different between the two studied groups. Despite the limited duration that women had to push, when the delayed approach was followed, fatigue and satisfaction after delivery did not differ between the two groups. In addition, perineal lacerations $\left(3^{\text {rd }}\right.$ and $4^{\text {th }}$ degree), episiotomy rates or need for oxytocin augmentation were not statistical significant different between the groups. As far as the neonatal outcomes are concerned, the risk of a low umbilical cord blood $\mathrm{pH}$ was higher with the use of delayed compared to immediate pushing (RR 2.24, 95\% CI 1.37 to 3.68). Low umbilical $\mathrm{pH}$ was defined as $\mathrm{pH}$ lower than 7.10 concerning the umbilical artery and pH lower than 7.15 concerning the umbilical vein. Apgar scores, admission to neonatal intensive care units, or need for resuscitation in the delivery room were not statistical significant different between the groups. When the care costs were analyzed, the intrapartum care cost for a woman using the delayed approach was increased by $\$ 68.22$. Nevertheless, the postnatal care costs were not different between the two groups. The authors came to conclusion supporting the opinion, that as a certain, evidencebased conclusion cannot be made, the method that will be used should be chosen according to woman's preference and clinical status. The results of the study are summarized in Table 2 .

Tuuli et $\mathrm{al}^{31}$, also ran a meta- analysis and one significant outcome was that they found an increase in spontaneous vaginal delivery rate in the group following the delayed pushing technique compared to the group adopting the immediate pushing method (61.5\% compared with $56.9 \%$, pooled RR 1.09 , 95\% CI 1.03-1.15). Interestingly, when this outcome was analyzed in two sup-groups regarding the quality of the trials, this difference was only statistically sig- 
Table 2. Synopsis of the articles concerning the timing of pushing

\begin{tabular}{llll}
\hline STUDY-AUTHORS- YEAR- & STATISTICAL SIGNIFICANT & NON-STATISTICAL & AUTHORS' CONCLUSION- \\
ELIGIBLE WOMEN & OUTCOMES & SIGNIFICANT OUTCOMES & SUGGESTIONS
\end{tabular}

Cochrane Analysis Lemos et al $^{1} \mathbf{2 0 1 7}$

- nulliparus or multiparus

- age 17 to 42 years old

- low risk

- absence of intrapartal complications

- gestational age: 37 to 42 weeks

- vertex presentation

- alive - single fetus

- with epidural analgesia

Meta- Analysis

Tuuli et al $^{31} 2012$

Waiting time: 60 to 180 minutes

- nulliparus or multiparus

- with epidural analgesia

\section{Maternal:}

- Increased duration of the second stage of labour in the delayed pushing group

*both nulliparus and multiparus

(MD 56.40, 95\% CI 42.05 to

70.76).

*nulliparus (MD 56.12, 95\% CI

39.29 to 72.96$)$

*multiparus (MD 38.80, 95\% CI

29.16 to 48.44 )

- Decreased duration of active second stage, delayed pushing group.

*both nulliparus and multiparus (MD -19.05, 95\% CI -32.27 -5.83).

*nulliparus(MD -21.30, 95\% CI

-36.87 to -5.73 )

* multiparus (MD $-11.35,95 \%$ CI

-18.19 to -4.51 )

- Increased spontaneous vaginal delivery rates in the delayed pushing group (RR 1.07, 95\% CI 1.03 to 1.11 )

\section{Neonatal}

- Higher risk of a low umbilical cord blood $\mathrm{pH}$ in delayed pushing group (RR 2.24, 95\% CI 1.37 to 3.68 )

\section{Costs}

- Increased intrapartum cost (\$68.22) for women in the delayed pushing group

\section{Maternal:}

In the delayed group

- Higher spontaneous vaginal delivery rate (RR 1.09, 95\% CI

1.03-1.15).

- Decreased instrumental vaginal delivery rates (primiparus: RR 0.89 95\% CI 0.81- 0.98)

- Increased overall duration of labour (MD: 56.92 minutes, 95\%

CI 42.19-71.64)
Maternal:

- Perineal Lacerations (3rd and 4th degree)

- Episiotomy

- Oxytocin augmentation

- Instrumental Vaginal Delivery

- Rotational/ midpelvic/ posterior forceps

- Caesarean Section

- Postpartum hemorrhage

- Fatigue after Delivery

- Maternal Satisfaction

- Fecal Incontinence

- Dyspareunia

Neonatal

- Admission to neonatal intensive care

- five- minute Apgar score less than seven

- Delivery room resuscitation

Costs

- pospartum costs
In absence of strong evidence supporting either the delayed or the immediate pushing technique, the method that will be used should be chosen according to woman's preference and clinical status.
Maternal:

- caesarean section

- instrumental vaginal delivery (primiparus+multiparus)

- perineal lacerations

- perineal trauma

- postpartum hemorrhage

- maternal fatigue

- maternal satisfaction
Due to the major uncertainty regarding the effects of the delayed pushing technique, well-organized trials have to be done so as a conclusive result can be made. 
Table 2. Synopsis of the articles concerning the timing of pushing (condinued)

\section{STUDY-AUTHORS- YEAR- STATISTICAL SIGNIFICANT ELIGIBLE WOMEN OUTCOMES \\ - Decreased active duration of the second stage *primiparus+multiparus: MD -21.98 minutes, $95 \%$ CI -31.29 to -12.68$)$. \\ *primiparus: MD:-25.23 minutes, $95 \% \mathrm{CI}-33.85$ to $-16.62$ \\ *multiparous: MD:-11.10 minutes, $95 \%$ CI -18.10 to -4.18 \\ - Increased risk for maternal fever (RR 1.88, 95\% CI 1.31- 2.71)}

\section{Meta-analysis \\ Brancato et $\mathrm{al}^{22} 2007$ \\ Waiting time: up to 60 minutes \\ - nulliparus or multiparus \\ - absence of intrapartal complications or maternal existing disorders \\ - gestational age: full term \\ - spontaneous or induced labour \\ - alive - single fetus \\ - with epidural analgesia}

\section{Maternal:}

\section{In the delay group}

- Increased possibility of spontaneous vaginal birth (RR: 1.08; CI: 1.01-1.15)

- Decreased risk of instrumental delivery (RR: 0.77; CI: 0.710.85),

- Decreased time spent pushing during second stage (MD: - 0.19 hours; CI: -0.27 to 0.12).

\section{Randomized Clinical Trial Fitzpatrick et al $^{32}$ 2002 Waiting time: $60 \mathrm{~min}$}

- absence of intrapartal complications or maternal existing disorders

- gestational age: 37 to 42 weeks

- spontaneous or induced labour

- cephalic presentation

- alive - single fetus

- with epidural analgesia
Maternal:

In the delayed pushing group

- Increased overall duration of labour (427 vs $480 \mathrm{~min}$, $\mathrm{P}=0.005$ )

- Increased duration of the second stage of labour (60 vs 120 min, $\mathrm{P}<0.001$ )

- Increased duration of oxytocin administration (199 vs 281 min, $\mathrm{P}=0.05$ )

\section{NON-STATISTICAL SIGNIFICANT OUTCOMES}

\section{Neonatal}

- cord $\mathrm{pH}$

- cord gases

- Apgar scores

- admission to NCU

- neonatal sepsis

Maternal:

- Caesarean Sections

- Episiotomies

- Perineal Lacerations

\section{AUTHORS' CONCLUSION- SUGGESTIONS}

The delayed pushing technique is beneficial for the mother and it is suggested that healthy women in labour, with lack of any complication and with epidural analgesia should be encouraged to push when they feel the urge.
Maternal:

- Duration of pushing

- Instrumental vaginal delivery rate

- Caesarean Section rate

- Episiotomy

- 2nd -3rd degree perineal lacerations

- Dyspareunia

- Postpartum bowel function

- Patient satisfaction

Neonatal

- Admission to neonatal intensive care

- Median cord pH
Adopting the delayed pushing technique does not benefit neither the mother nor the neonate and there is not a strong evidence suggesting the establishment of this method in medical daily routine. 
Table 2. Synopsis of the articles concerning the timing of pushing (condinued)

\begin{tabular}{l}
\hline STUDY-AUTHORS- YEAR- \\
ELIGIBLE WOMEN \\
Retrospective cohort \\
study Frey et al ${ }^{33}$ \\
2012 Waiting time: 60 \\
minutes or more \\
- nulliparous or \\
multiparous \\
- absence of intrapartal \\
complications, existing \\
maternal disorders or \\
fetal abnormalities \\
- gestational age: full term \\
- alive - single fetus \\
- with or without epidural \\
analgesia
\end{tabular}
OUTCOMES

Maternal:

- In the delayed group

- Decreased rates of spontaneous vaginal delivery (aOR: 0.54 , $95 \%$, CI: 0.42 to $0.68, \mathrm{p}<0.01$ )*

- Increased rates of cesarean birth $(3.2 \%$ vs $1.4 \%$, aOR 2.27 , $95 \%$ CI 1.28 to $\left.4.02, \mathrm{p} 1 / 4^{1 / 0.01}\right)^{*}$

- Increased rates of operative vaginal delivery $(19.3 \%$ vs $12.0 \%$, aOR $1.75,95 \%$ CI 1.36 to $2.24, \mathrm{p}<0.01$ ).*

- Increased risk for maternal fever $(10.9 \%$ vs $6.0 \%$, aOR $1.77,95 \%$ CI 1.28 to $2.46, \mathrm{p}<$ 0.01 )

- Decreased risk for PostPartum Hemorrhage (PPH 0.6\% vs $2.0 \%$, aOR $0.31,95 \%$ CI 0.10 to 0.97, p 1/4 0.03).

- Increased duration of second stage of labour (MD $129 \mathrm{~min}$ vs 22 min, $\mathrm{p}<0.01$ )

- Decreased duration of active second stage (MD 26 min vs 10 min, $\mathrm{p}<0.01$ )

*when both nulliparous and muliparous were stratified

Neonatal

- Increased possibility of umbilical artery $\mathrm{pH}<7.2$ for infants born by mothers adopting the delayed pushing technique $0.6 \%$ vs $2.0 \%$, aOR $0.31,95 \%$ CI 0.10 to $0.97, \mathrm{p}=$ 0.03).

Multicentre Randomized Trial Cahill et al ${ }^{34} 2018$ Waiting Time: $60 \mathrm{~min}$

- nulliparous

- gestational age: >37 weeks

- single fetus, without any anomaly

- low risk

- with epidural analgesia
Maternal:

In the immediate pushing group:

- Decreased duration of the second stage of labor (MD: -31.8 minutes [ $95 \% \mathrm{CI},-36.7$ to -26.9 minutes], $\mathrm{P}<.001$ ).

- Increased duration of active pushing (MD: 9.2 minutes [95\% CI, 5.8 to 12.6 minutes], $\mathrm{P}<.001)$.

\section{NON-STATISTICAL} SIGNIFICANT OUTCOMES

\section{Maternal:}

- No difference of the mode of delivery in nulliparous women

- Medication to treat PPH

- Need for blood transfusion

- Rates of retained placenta

- Shoulder dystocia

\section{Neonatal}

- Admission to NCU

- Need for high-acuity nursery admission

- Apgar scores

\section{AUTHORS' CONCLUSION- SUGGESTIONS}

The delayed pushing technique carries negative effects for both the mother and fetus and should not be encouraged. The indicating factor for this is the prolonged second stage of labour. However, due to the limitations of the study, further research is required in order to reach in more curtain conclusions

\section{Maternal:}

- Spontaneous vaginal delivery

- Caesarean Delivery

- Instrumental Vaginal Delivery

- Indications for any type of operational delivery

- Endometritis

- Perineal lacerations

- maternal satisfaction

- estimated blood loss

- need for transfusion 
Table 2. Synopsis of the articles concerning the timing of pushing (condinued)

\begin{tabular}{|c|c|c|c|}
\hline $\begin{array}{l}\text { STUDY-AUTHORS- YEAR- } \\
\text { ELIGIBLE WOMEN }\end{array}$ & 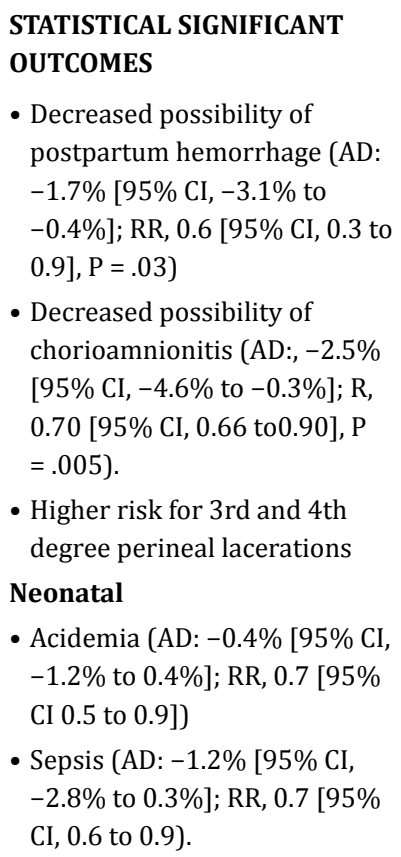 & $\begin{array}{l}\text { NON-STATISTICAL } \\
\text { SIGNIFICANT OUTCOMES } \\
\text { Neonatal } \\
\text { - Neonatal morbidity } \\
\text { - Shoulder dystocia } \\
\text { - admission to NCU }\end{array}$ & $\begin{array}{l}\text { AUTHORS' CONCLUSION- } \\
\text { SUGGESTIONS } \\
\text { The adoption of the delayed } \\
\text { pushing technique in women } \\
\text { with epidural analgesia } \\
\text { prolongs the second stage } \\
\text { of labour, carrying negative } \\
\text { impacts for both the mother } \\
\text { and fetus, without any effect } \\
\text { in spontaneous vaginal } \\
\text { delivery rates. Therefore, it } \\
\text { should not be recommended. }\end{array}$ \\
\hline
\end{tabular}

nificant in trials with small numbers of participants and low quality of methodology ("high quality": $59.0 \%$ compared with $54.9 \%$, pooled RR $1.07,95 \%$ CI $0.98-1.26$ vs "low quality": $81.0 \%$ compared with $71.0 \%$, pooled RR $1.13,95 \%$ CI $1.02-1.24$ ) . In addition, this difference remained statistically significant when the women were sub-grouped by parity and all the trials were included. However, caesarean and instrumental vaginal delivery rates were the same among the studied groups when both primiparus and multiparus women were analyzed. When the analysis stratified only the primiparus women, a statistical significant decrease in instrumental vaginal delivery rate was recorded ( $R R$ $0.89,95 \%$ CI 0.81- 0.98). Concerning the duration of labour, outcomes were in line with the Cochrane Analysis' results: The overall duration of labour was increased by 57 minutes in the delayed group MD: 56.92 minutes, 95\% CI 42.19-71.64) and this difference showed a remarkably extend in the subgroup of the primiparous women compared to multiparus (MD:-25.23 minutes, 95\% CI -33.85 to -16.62 compared with MD:-11.10 minutes, $95 \%$ CI -18.10 to -4.18$)$. Nevertheless, time spending for pushing, was statistically significant decreased by 20 minutes in the women adopting the delayed pushing technique (MD -21.98 minutes, 95\% CI -31.29 to -12.68). Moreover, a difference of maternal outcomes regarding to the perineal lacerations, postpartum hemorrhage, fatigue and satisfaction and neonatal outcomes regarding cord $\mathrm{pH}$ or cord gases, Apgar scores, need for admission to NCU or neonatal sepsis, was absent among the two studied groups. Despite the absence of a statistical significant difference for neonatal outcomes, was recorded a tendency for worse neonatal image, when the two larger trials were stratified. Finally, women following the delayed pushing technique were twice more likely to present fever (RR 1.88, 95\% CI 1.31-2.71) and this possibility was aligned with the time of delay (the longer the pushing efforts were delayed, the more likely the presence of fever). Brancato et al ${ }^{51}$ 
in their meta-analysis which took place in 2007, came to an agreement with the outcomes of Tuuli's analysis. The results of the two meta-analyses are summarized in Table 2. The outcome concerning the reduction in the instrumental vaginal deliveries, has been criticized by several subsequent articles, claiming that in these trials the percentage of the usage of instruments for delivery were considerably higher in both the arms of the studies than in the current daily medical routine and therefore this results requires redefining ${ }^{28}$.

Fitzpatrick's trial ${ }^{3}$ which has been considered as "high quality" by the Cochrane Analysis, had concluded to some interesting results which are presented below. The overall duration of labour was increased by 53 minutes for the women included in the delayed pushing group and this difference is statistically significant. However, the duration of pushing did not differ among the two groups and this contradicts the Cochrane Analysis' results. Additionally, no difference concerning instrumental delivery rate, perineal lacerations, perineal pain, episiotomies rate, maternal satisfaction and postpartum bowel function, was recorded. Finally, no one of the neonatal outcomes studied, were statistically significant different in the two groups.

Conversely, two more recent trials (Frey et $\mathrm{al}^{33}$ and Cahill et $\mathrm{al}^{34}$ ) concluded that the delayed pushing method carries negative impacts for both the mother and fetus. Frey's trial has several limitations such as the retrospective design of the study, the major difference in the numbers of women included in the two arms of the study (delayed pushing: 471 women vs immediate pushing: 4819 women) and the different baseline characteristics of the participants. However, their results are quite interesting and they are presented in Table 2. Cahill's trial is randomized, with large sample of participants and its methodology was designed with high quality standards. The authors found that the possibility of a spontaneous vaginal delivery were not different in women adopting the immediate or the delayed pushing technique (85.9\%vs $86.5 \%$, respectively). When the immediate pushing technique was followed, the duration of the second stage was increased (MD: -31.8 minutes [95\% CI, -36.7 to -26.9 minutes], $P<.001$ ), although the active second stage was decreased in duration (MD, 9.2 minutes [95\% CI, 5.8 to 12.6 minutes], $P<.001$ ). The women who adopted the immediate pushing technique were less likely to present postpartum hemorrhage (absolute difference, $-1.7 \%$ [95\% CI, $-3.1 \%$ to $-0.4 \%$ ]; RR, 0.6 [95\% CI, 0.3 to 0.9 ], $P=$ .03 ), and chorioamnionitis (absolute difference, $-2.5 \%$ [ $95 \% \mathrm{CI},-4.6 \%$ to $-0.3 \%$ ]; RR, 0.70 [95\% CI, 0.66 to 0.90$], P=.005$ ), although the difference for endometritis was not statistically significant. Despite the equivalent rates of perineal lacerations among the two arms of the study, women following the immediate pushing technique were more likely to have a third and fourth degree perineal laceration (absolute difference, $0.9 \%$ [95\% CI, $-0.8 \%$ to 2.6\%]; RR, 1.2 [95\% CI, 1.0 to 1.4], $P=.02$ ). Regarding the neonatal outcomes, there was not recorded any difference in neonatal morbidity between the two groups. However, neonates whose mother had followed the delayed pushing technique, were in higher risk for academia (absolute difference, $-0.4 \%$ [95\% CI, $-1.2 \%$ to $0.4 \%$ ]; RR, 0.7 [95\% CI 0.5 to $0.9]$ ) and sepsis (absolute difference: $-1.2 \%$ [95\% CI, $-2.8 \%$ to $0.3 \%$ ]; RR, 0.7 [ $95 \% \mathrm{CI}, 0.6$ to 0.9 ). The results of the study are summarized in Table 2. It is important to be mentioned that the trial was only completed by $75 \%$, due to concerns regarding the higher possibility of maternal morbidity and postpartum hemorrhage for women adopting the delayed pushing technique.

\section{Conclusion}

Taking into account all the information men- 
tioned above, it is clearly noticed that a conclusive result which allows a worldwide practice concerning the optimal type or the ideal timing of the onset of pushing efforts, is hard to be obtained. Concerning the type of pushing, controversies are met in the worldwide literature, resulting a confusion between the obstetric community about which method is best for both the mother and the baby. When the timing of pushing is concerned, the two latest trials stands against the uniform establishment of the delayed pushing technique, while some trials that took place in the first decade of the millennium argued that this technique is more than beneficial for women with epidural analgesia. As a certain recommendation is impossible, we embraced the opinion of Lemos et $\mathrm{al}^{1}$, suggesting that the decision of technique for both the timing and the type that will be followed in labour should be made according to women's preference and clinical status.

\section{References}

1. Lemos A, Amorim MMR, Dornelas de Andrade A, de Souza AI, Cabral Filho JE, Correia JB. Pushing/bearing down methods for the second stage of labour. Cochrane Database of Systematic Reviews 2017,Issue3.Art.No.CD009124.DOI:10.1002/14651858. CD009124.pub3.

2. Parnell C, Langhoff-Roos J, Iversen R, Damgaard P. Pushing in the expulsive phase of labour. Ugeskrift for Laeger 1993;155:2259-62.

3. Roberts J, Goldstein S, Gruener J, Maggio M, Mendez- Bauer C. A descriptive analysis of involuntary bearing-down efforts during the expulsive phase of labor. J Obstet Gynecol Neonatal Nurs 1987;16:48 -55.

4. Roberts JE. The "push" for evidence: management of thesecond stage. Journal of Midwifery and Womens Health 2002;47:2-15

5. Aldrich C, D'Antona D, Spencer J, Wyatt J, Peebles
D, Deply D, et al. The effect of maternal pushing on fetal cerebral oxygenation and blood volume during the second stage of labour. Br J Obstet Gynaecol 1995;102:448 -53.

6. Barnett MM, Humenick SS. Infant outcomes in relation to second stage labor pushing method. Birth 1982;9:221- 8.

7. Caldeyro-Barcia R, Giussi G, Storch E, Poseiro JJ, Lafaurie N, Kettenhuber K, et al. The bearingdown efforts and their effects on fetal heart rate, oxygenation and acid-base balance. J Perinat Med 1981;9:63-7.

8. Simpson KR, James DC. Effects of immediate versus delayed pushing during second-stage labor on fetal well-being. NursRes 2005;54:149 -57.

9. Cunningham FG, Macdonald G. Williams Obstetrics. New York: McGraw-Hill, 2001.

10. Schaffer JI, Bloom SL, Casey BM, McIntire DD, Nihira MA, Leveno KJ. A randomized trial of the effects of coached vs uncoached maternal pushing during the second stage of labor on postpartum pelvic floor structure and function. American Journal of Obstetrics and Gynecology 2005;192: 1692-6.

11. Thomson A. Maternal behavior during spontaneous and directed pushing in the second-stage of labour. J Adv Nurs 1995;22:1027-34.

12. Yeates D, Roberts J. A comparison of two bearingdown techniques during second stage of labor. J Nurse Midwifery 1984;29:3-11.

13. Aderhold KJ, Roberts JE. Phases of second stage labor - Four descriptive case studies. J Nurse Midwifery 1991;36:267-75.

14. Piquard R, Schaefer A, Hsiung R, Dellenbach P, Haberey P. Are there two biological parts in the second stage of labor? Acta Obstet Gynecol Scand 1989;68:713- 8.

15. Roemer VM, Harms K, Buess H, Horvath TJ. Response of fetal acid-base balance to duration of second stage labour. Int J Gynecol Obstet 1976;14:455-71 
16. Prins M, Boxem J, Lucas C, Hutton E. Effect of spontaneous pushing versus Valsalva pushing in the second stage of labour on mother and fetus: a systematic review of randomised trials. BJOG 2011;118:662-670.

17. Bloom S, Brian M. Casey B.M, Schaffer J.I, McIntire D.D, Leveno K.J. A randomized trial of coached versus uncoached maternal pushing during the second stage of labor. American Journal of Obstetrics and Gynecology, 2006; 194: 10-3

18. Perry L, Porter CV. Pushing technique and the duration of the second stage of labor. W V Med J 1979;75:32-4.

19. Buhimschi CS, Buhimschi IA, Malinow AM. Pushing in labor: performance and not endurance. Am J Obstet Gynecol 2002;186:1339-44.

20. Yildirim G, Beji NK. Effects of pushing techniques in birth on mother and fetus: a randomized study. Birth 2008; 35:25-30.

21. Hansen SL, Clark SL, Foster JC. Active pushing versus passive fetal descent in the second stage of labor: a randomized controlled trial. Obstetric \& Gynecology 2002;99(1):29-34

22. Brancato R.M, Church S, Stone P. W. A Meta-Analysis of Passive Descent Versus Immediate Pushing in Nulliparous Women With Epidural Analgesia in the Second Stage of Labor. JOGNN, 37 , 4-12; 2008. DOI: 10.1111/J.1552-6909.2007.00205.x

23. Lieberman E, Davidson K, Lee-Parritz A, Shearer E. Changes in fetal position during labor and their association with epidural analgesia. Obstet Gynecol 2005;105:974-82.

24. Senecal J, Xu X, Fraser WD, for the PEOPLE (Pushing Early Or Pushing Late with Epidural) study group. Effect of fetal position on second stage duration and labor outcome. Obstet Gynecol 2005;105:763-72.

25. Mayberry LJ, Hammer R, Kelly C, True-Driver B, De A. Use of delayed pushing with epidural anesthesia: findings from a randomized, controlled trial. J Perinatol 1999;19:26 -30.
26. Maresh M, Choong KH, Beard RW. Delayed pushing with lumbar epidural analgesia in labour. $\mathrm{Br}$ J Obstet Gynaecol 1983; 90:623-7.

27. Kelly M, Johnson E, Lee V, Massey L, Purser D, Ring $\mathrm{K}$, et al. Delayed versus immediate pushing in second stage of labor. MCN; American Journal of Maternal Child Nursing 2010;35(2):81-8.

28. Fraser WD, Marcoux S, Douglas J, Goulet C, Krauss I, for the PEOPLE Study Group. Multicentre trial of delayed pushing for women with continuous epidural. Acta Obstetricia et Gynecologica Scandinavica 1997;76 Suppl (167:1):45.

29. Minato JF. Is it time to push? Examining rest in secondstage labor. AWHONN Lifelines 2001;4:20-3.

30. Walton P, Reynolds F. Epidural analgesia and instrumental delivery. Anaesthesia 1984;39:218- 223.

31. Methodius G. Tuuli M.G, Frey H.A, Odibo A.O., Macones G.A, Cahill A.G.

32. Immediate Compared With Delayed Pushing in the Second Stage of Labor. A Systematic Review and Meta-Analysis. ACOG 2012, ISNN: 0029-784412

33. Fitzpatrick M, Harkin R, McQuillan R, O’Brien C, P. Ronan O'Connell P.R, O'Herlihy V. A randomised clinical trial comparing the effects of delayed versus immediate pushing with epidural analgesia on mode of delivery and faecal continence. RCOG 2002 Br J Obstet Gynaecol 109, pp. 1359-1365

34. Frey HA, Tuuli MG, Cortez S, et al. Does delayed pushing in the second stage of labor impact perinatal outcomes? Am J Perinatol. 2012;29(10): 807814. doi:10.1055/s-0032-1316448

35. Cahill AG, Srinivas SK, Tita AT, Caughey AB, Richter HE, Gregory WT, et al. Effect of immediate vs delayed pushing on rates of spontaneous vaginal delivery among nulliparous women receiving neuraxial analgesia: a randomized clinical trial. JAMA 2018;320:1444-54.

36. WHO recommendations: intrapartum care for a positive childbirth experience. ISBN 978-92-4-155021-5 
37. Fraser WD, Cayer M, Soeder BM, Turcot L, Marcoux S, for the PEOPLE (Pushing Early Or Pushing Late with Epidural) study group. Risk factors for difficult delivery in nulliparas with epidural analgesia in second stage of labor. Obstet Gynecol 2002;99:409-18.

38. Lilford RJ, Glanville JN, Gupta JK, Shrestha R, Johnson $\mathrm{N}$. The action of squatting in the early postna- tal period marginally increases pelvic dimensions. British Journal of Obstetrics and Gynaecology 1989;96(8):964-6.
Received 28-11-2019

Revised 6-12-2019

Accepted 12-12-2019 